Final submission to Research in Mathematics Education

\title{
Exploring social patterns of participation in university-entrance level mathematics in England
}

\author{
Andrew Noyes \\ University of Nottingham
}

\begin{abstract}
In recent years in England there has been considerable attention given to a range of apparent crises in mathematics education, one of which has been the long term decline of participation in universityentrance level (Advanced or A) mathematics. Given the negative impact upon mathematics participation of Curriculum 2000, together with the government's emphasis on Science Technology Engineering and Mathematics (STEM) subjects, the political intent to increase participation in Advanced level mathematics is clear. This paper uses the National Pupil Database (NPD) to develop a descriptive statistical account of how completion of Advanced level mathematics varies along the social axes of SES, ethnicity and gender. The process of working with the NPD is discussed in some depth in order to clarify the processes involved in this type of quantitative analysis and to illustrate how this analysis can be used to raise questions about who is doing what mathematics in the post- 16 agerange.
\end{abstract}

\section{Keywords}

University-entrance level mathematics, Advanced mathematics, participation, National Pupil Database.

\section{Introduction}

For some time in England there has been a great deal of concern about declining participation rates in university-entrance level mathematics (i.e. Advanced or A level). Recent reports (Matthews \& Pepper, 2007; Roberts, 2002; Smith, 2004) have all highlighted this problem which has been ongoing since the 1980s. The introduction of Curriculum 2000 has been called "a disaster for mathematics" (Smith, 2004, 8) as the newly structured qualification had relatively low pass rates compared to other subjects with the effect that participation dropped by around $20 \%$ in the following two years. Only now are there signs of an upturn in participation following further changes being made to the A level curriculum in 2004.

In England, young people complete their compuslory schooling at age 16 (Year 11) with the General Certificate of Secondary Education (GCSE) qualifications. Obtaining five or more higher grades $\left(\mathrm{A} *_{-} \mathrm{C}\right)$ allows students access to a wide range of further educational opportunities. The majority of those achieving this level at GCSE proceed to the traditional academic track of Advanced level awards (General Certicificate of Education or GCE). These are the standard university-entrance qualifications and most students would study three or four subjects over the following two years, up to the age of 18 (Year 13). Sometimes a student might complete only half of one of these two-year, modular A level courses and receive an Advanced Supplementary (AS) award. Advanced level mathematics is a pre-requisite for most Science, Technology, Engineering and Mathematics (STEM) courses in higher education and has been shown to increase future earning potential (Wolf, 2002).

Maintaining the flow of suitably qualified mathematicians (and scientists) into the economy is understood to be critical in maintaining future economic prosperity and international competitiveness (Gago, 2004). So there is considerable political will to reverse the downward trend of A level mathematics participation in England. The Qualifications and Curriculum Authority is currently 
investing substantial resources into developing more successful mathematics pathways for 14-19 year olds (QCA, 2008). However, in trying to address this situation it is important to ask whether this complex issue is fully understood. The data reported here come from a much larger study exploring the trajectories of learners of mathematics between 14 and 19 years of age. The Geographies of Mathematical Attainment and Participation (GMAP) Project is a multi-layered, mixed-methods study exploring regional patterns of attainment and participation and the roles of family, school and peers in creating these patterns. With a particular concern for social justice the project explores who gets to do what mathematics and where.

The most up-to-date analysis of participation in Advanced level mathematics is Matthews and Pepper's (2007) report for the Qualifications and Curriculum Authority (QCA) which charts the impact of Curriculum 2000 in mathematics (and a number of other subjects) and offers some useful overview statistics of participation. It is worth noting at this point that national analyses (e.g. Emery, 2007; Matthews \& Pepper, 2007) are normally based on data in the Department for Children Schools and Families' National Pupil Database (NPD) which means they only use results data (included all pass and fail grades). Such analyses can only be about those who completed courses and examinations and therefore are a measure of course completion and do not give the full picture of participation and attrition from Advanced level mathematics courses. Survey work in another strand of the GMAP Project indicates that about 10\% of students who begin Advanced level mathematics courses withdraw before completing any examinations, and that this is one of the highest attrition rates across the range of A level subjects.

Matthews and Pepper ask the question "who is doing A level mathematics?" and conclude that mathematics continues to be for a 'clever core' (17). They contend that the only way to increase A level mathematics participation would be through a process of democratisation in which recruitment would be more inclusive. Wiliam et at (1999) explored how the perceived gap between GSCE and A level mathematics study, in contrast with that in English for example, contributes to the idea that mathematics is hard. Behind any headline figures the patterns of starting, completing and of attainment at A level are socially differentiated by gender, SES and ethnicity. I focus on exploring these three social categorisations in the remainder of this paper.

A recent study by the Mathematics in Education and Industry group (MEI, 2008) has shown that there have been significant increases in AS entries in 2008. Nonetheless such 'good news' does not answer the question about who is studying mathematics at this level. Nor indeed does a continued focus on the headline statistics suggest who might be the student groups that are currently underrepresented. While there is some research on mathematics learning at A level (for example Brown, Brown, \& Bibby, 2008; Hernandez-Martinez et al., 2008; Mendick, 2005), much of which is qualitative, the aim in this paper is to complement this exisiting research with a quantitative contribution; specifically, by making use of the National Pupil Database (NPD).

\section{Investigating the structuring of mathematical 'choice' using the National Pupil Database}

At the heart of the theoretical framework of the GMAP Project is a critique of the notion of choice, a central tenet of neo-liberal education reforms in England which imagines the well-informed parent or student choosing freely from a range of alternatives in the education market. Although this notion of 'choice' has been central to English educational policy over the last fifteen years or more (Ball, Bowe, \& Gewirtz, 1996; Ball, Maguire, \& Macrea, 2000; Leckie \& Goldstein, 2009 forthcoming; Reay, Davies, David, \& Ball, 2001), the GMAP Project contends that to significantly increase participation in Advanced level mathematics would require better understanding of the social structuring of these 'choices'. Bourdieu explained that "we can always say that the individual makes choices, as long as we do not forget that they do not choose the principle of their choices" (Bourdieu \& Wacquant, 1989, 45). I am interested in establishing how these 'principles' are socially structured and I am seeking evidence of this in these national datasets. Drawing on Bourdieuan 
sociology Ball, Davies, David and Reay (2002) explain, in the context of their work on higher education choices, that

... sociologically speaking choice, the implementation of practical knowledge, is a highly problematic concept. It threatens all sorts of theoretical and ontological difficulties and needs to be handled with care. (51, my italics)

They proceed to point out that choice of higher education course and institution

...takes place within two registers of meaning and action. One is cognitive/performative and relates to the matching of performance to the selectivity of institutions and courses. The other is social/cultural and relates to the social classifications of self and institutions. (52)

I am considering how Bourdieu's 'principles' or Ball et al's 'classifications' emerge across the social categories of class, ethnicity and gender in the completion of university-entrance level mathematics. Having established, statistically and through the use of mapping technology, these social patterns in Advanced level mathematics completion the GMAP Project is exploring at the school level, through large scale questionnaire surveys and case study work, how the day-to-day practices of teachers and learners helps to structure such patterns. However, I focus here on sketching out the 'big picture' through quantitative analyses of data from the NPD. First I explain the processes by which datasets for my analysis are constructed. Then I report some descriptive statistics exploring the social makeup of the Advanced level mathematics cohort.

As a researcher who has, until now, largely written from qualitative data, I am surprised by just how similar the complex judgement processes are when working with these national datasets. In Gorard's (2008) recent analysis of participation in Higher Education, as it relates to the UK government's Widening Participation (WP) agenda, he helpfully explains that

...every analysis concerning patterns of participation must make, even by default, a bewildering number of decisions....and every analyst might quite reasonably make a different set of decisions. Unless these analytical compromises are clearly reported, there is a danger that debates about what is happening in WP will be misinterpreted by commentators as being about issues of substance, whereas they are, in reality, merely about differences in making these analytical decisions. (423)

Following Gorard's advice I dedicate a substantial part of this paper to explaining the decisions and 'analytical compromises' being made through the data cleaning process, particularly how I generated the four different datasets used herein. Recording this process is rather like leaving a trail through a maze providing a means of retracing one's steps, thus providing a record by which the validity of a particular sequence of actions can be tested and analyses verified. Even though my research aim is clear - to identify social patterns in Advanced level mathematics completion -, and thus the data cleaning process easier, I have to fight constantly the urge to retain a very wide range of variables. While this might be of interest later, in the meantime it can just confuse matters. The NPD datasets include hundreds of fields. I reduced these to include prior attainment (at the start of secondary school, GCSE and A level), various social background variables, schools attended and postcode data (for use with geodemographic mapping).

The Department for Children Schools and Families (DCSF) has accumulated vast amounts of data on pupil attainment and student social variables in its National Pupil Database. Each child has a unique pupil reference number and so it is possible to track their progress. However, although this presents a great opportunity for researchers, I should sound a note of caution. One of the major challenges to overcome when working with the NPD relates to the overwhelming scale of the data. The GMAP Project is focused on the two Government Office Regions (GOR) of the Midlands of England; that is a cohort of nearly 130,000 Year 11 students completing their compulsory schooling in any one year. 
For each of these students there are several hundred data items stored, many of which are of little relevance to any particular project or research question. Furthermore not all student records are complete; in fact many are missing one or more data items. Back to Gorard's warning, these omissions are likely to have an impact on any analysis that might be undertaken; hence the following section.

One of the useful features of the NPD data is the range of social measures that can be matched to results/school data. These social measures include ethnicity, gender and free school meal (FSM) eligibility. It also includes ACORN ${ }^{1}$ and IDACI $^{2}$ (Income Deprivation Affecting Children Index) scores which are proxy measures of socio-economic status (SES), and thereby social class, based on a student's address. Free school meals is a rather clumsy binary category at the individual level. While I recognise that the ACORN and IDACI are imprecise measures, at least they are more sensitive to particular neighbourhood characteristics (but I note that they are not ascribed to an individual). I have used the IDACI score in this paper as it is more usefully presented in the NPD. I have grouped students into five IDACI quintiles, based on national figures, for ease of comparison. There are between 21 and 24 thousand students in each of these quintiles for the Midlands cohort being examined herein (dataset $\mathrm{D}$ - see below)

As explained above, I use the term participation in the following sense: as the datasets being used are not able to tell us who completed part of a course but only those who completed a qualification and were examined, by participation I mean completion of a full course of study and sitting the exam, which might have resulted in either a pass or fail grade.

\section{Constructing the datasets}

I begin with a dataset of 128,991 Year 11 students in the East and West Midlands Government Office Regions of England in 2005. Not all students complete their mathematics GCSE in Year 11, so this dataset covering Y11 students will include some who have taken mathematics early and might or might not have then completed another mathematics qualification (e.g. GCSE statistics, a Free Standing Mathematics Qualification ${ }^{3}$ or AS Mathematics). This is potentially messy but concerns only a small proportion of students $(7938,6 \%$ of the cohort). Less than one third of these achieved the $A *-B$ grade typically required to start an A level course so many would have retaken their GCSE mathematics. This makes the analysis trickier. So a student who achieved a grade $\mathrm{C}$ in year 10 and an A in year 11 has the same recorded GCSE grade for mathematics as one who achieved A the first time around in year 11, and another with the same A grade in year 10. However these two students might have had quite a different experience. This also means that the mathematics grade in my analyses in this paper does not distinguish between the retaking student and the one who achieved grade A in year 10. I have chosen to ignore this as I am interested in post-GCSE participation and early entry is probably a school choice rather than a student one. That is not to say that early entry does not have an impact on learner experiences and later participation but rather that there is not sufficient space here to explore this problem in sufficient depth. In the dataset I retain students' initial and final mathematics GCSE grade along with a variable to account for whether students were entered earlier than the norm. Similarly, I have overlooked the very small number of these students who then completed an Advanced level (e.g. AS mathematics) in Y11 (59 students). Again, the reason for this is that I am modelling the pattern of completing mathematical study beyond GCSE.

A few duplicates (78) were removed or merged and all students attaining no GCSE grades in any subject were also removed. This left a total of 121,524 students. My working datasets required the merging of three different NPD datasets: GCSE results, A level results and social background measures. This can be done in two different ways: Candidate Information tables record institutions and total GCE points as well as outlining the grades obtained in a number of subjects. Alternatively, 
Results tables provides more detailed data on awards, awarding bodies, grades and year taken, much of which is unnecessary for my purposes. Although the match from these two options is very good it is not perfect. I decided to use the Candidate Information tables but checked for discrepancies with Results tables and, where possible, made corrections to get the most accurate combination of the two sources.

Due to the structure of the DCSF's data collection process, some of the NPD social variables which are collected in the Pupil Level Annual School Census (PLASC) are only available for a proportion of these students (92.5\%) in Year 11 and this is linked to school type: independent schools, for example, do not report ethnicity. However, the situation worsens beyond GCSE due to a large proportion of the cohort moving into Further Education and Sixth Form colleges where these social variables are also not reported. So, I matched the PLASC data at the end of year 11 to limit the impact of this data loss. Rather than removing all of the students with missing PLASC data, I constructed four different levels of the dataset and use these for slightly different analyses in the remainder of the paper. At each stage of the analysis, I use the dataset which retains the most relevant data. This means that comparisons between some of the tables cannot be made directly but is arguably a more honest, albeit always partial, view. The four datasets are as follows:

\section{A. All Year 11 students in 2005 including matched AS/2 level mathematics data where} appropriate. This is the largest dataset (121,524 students) and would allow for gender or institution analysis of all GCSE results. This can also provide a benchmark for comparison with sets $\mathrm{B}, \mathrm{C}$ and $\mathrm{D}$.

B. Year 11 students (2005) who then completed any Advanced level qualifications (by 2007) and therefore might potentially have done some mathematics. This removes all of the students not continuing to Advanced level study. This dataset still includes students without social data, e.g. those from independent sector, FE, etc. The vast majority of GCSE grade C candidates do not continue their study of mathematics at Advanced level. Many of these students (and indeed some attaining grade B) were entered for the Intermediate tier at GCSE (as opposed to the Higher and Foundation tiers) and so in most schools would be deterred from studying AS level. The typical requirement is that students have achieved a GCSE grade A*-B following the Higher tier (Matthews \& Pepper, 2007). The NPD does not give us this data but it might well make a significant difference to analyses of post-16 participation. Moreover, just including students achieving grade $\mathrm{C}$ and above in mathematics retains many students who have not achieved the normal entry requirement to Advanced level courses of 5 $\mathrm{A}^{*}$-C grades at GCSE (including English and mathematics). Across the East and West Midlands in 2005, 63,134 students achieved a grade $\mathrm{C}$ or above in mathematics by the end of Y11, of which 9,858 did not get $5 \mathrm{~A}^{*}$-C grades. However, 648 of these did complete some $\mathrm{AS} / 2$ mathematics later. Even though this is a small proportion of this data set, it seems better to retain them, despite the fact that they have not attained $5 \mathrm{~A} *$-Cs. Rather, I have retained those students who achieved mathematics grade $\mathrm{C}$ and are recorded in the NPD as having completed any GCE level qualification in 2006 or 2007, that is those continuing their education to Advanced level courses. Those who appear to have moved out of formal education are omitted. The result is a set of 41,176 students who completed any A levels.

C. Year 11 (2005) who then completed some Advanced level qualifications (by 2007) and for whom social data is available. This dataset allows for a detailed analysis of SES categories within state schools. However, this is problematic as, due to the intersections of SES, ethnicity and gender, the loss of data from independent schools will have a differential impact on further analysis on, for example, participation by various ethnic groups. Moreover, this study is only of the Midlands of England and the proportions of various ethnic groups are 
no doubt different in the national population (and would certainly be different for London). All of this needs to be remembered when interpreting the data. In order to carry out meaningful analyses I want cases that include measures of socio-economic status (e.g. IDACI/ACORN/FSM), ethnic group and gender. This leaves 36,696 students.

D. All of dataset A for whom matched social data is available. Following the removal of all those from dataset A for whom social data is not available (including all independent school students) this dataset is further reduced by a small amount (less than $1 \%$ ) to include only those students in mainstream secondary schools, which leaves 112,289 students.

All of the datasets include a range of attainment and social data, most of which is directly taken from the NPD but there are a few extra variables which have been constructed. One of these is the level of participation in A level mathematics (Mathematics, Further Mathematics or Use of Mathematics). This is graduated from AS Mathematics to full A-level in both Mathematics and Further Mathematics to give the categories P0-P4:

- P0: Advanced level students not completing any mathematics;

- P1: Students typically completing one year of mathematics (i.e. AS);

- P2: Students completing a two-year A level mathematics programme;

- P3: Students who have also completed an AS in Further Mathematics;

- P4: Students have taken two full A levels (Mathematics and Further Mathematics)

The 16 students completing two AS awards were included with the much larger group of single A2 students as they have done a similar volume of mathematics. There are a small group of students who have taken Statistics AS and A level and I have counted these as equivalent to Mathematics AS and A level. There are some issues with this in terms of progression to mathematically demanding courses in higher education but in the context of exploring participation in Advanced level mathematics this merging is reasonable. Table 1 shows the numbers of students in each $\mathrm{P}$ category, out of all Advanced level students in the region.

\begin{tabular}{ccc} 
Participation Level & Frequency & Percent \\
\hline P0 & 30000 & 72.9 \\
P1 & 3116 & 7.5 \\
P2 & 6545 & 15.9 \\
P3 & 656 & 1.6 \\
P4 & 859 & 2.1 \\
Total & 41176 & 100 \\
\hline
\end{tabular}

Table 1: Students completing various levels of AS/2 mathematics out of all those who completed some AS/2 qualification by end Year 13 (Dataset B)

\section{Analysing completion of any Advanced level mathematics}

Firstly I consider who is taking part in any A-level mathematics, from those completing an AS over two years to those completing Mathematics and Further Mathematics at A2. This is summarised by GCSE grade (see Table 2). Note that this is from Dataset B, that is all those students who completed an AS/A level qualifications (i.e. stayed on a GCE track to Year 13) so the B and C grade figures would be lower if using the whole Year 11 population (Dataset A). 
Participation in

\begin{tabular}{cccccc} 
AS/2 Mathematics & $\mathrm{A}^{*}(4232)$ & $\mathrm{A}(9218)$ & $\mathrm{B}(14608)$ & $\mathrm{C}(13118)$ & Total \\
\hline No & $760(18.0)$ & $4317(46.8)$ & $12153(83.2)$ & $12770(97.3)$ & $30000(72.9)$ \\
Yes & $3472(82.0)$ & $4901(53.2)$ & $2455(16.8)$ & $348(2.7)$ & $11176(27.1)$ \\
\hline
\end{tabular}

Table 2. Completion of any AS/2 mathematics by GCSE grade with percentages in parentheses (Dataset B).

As is well known, the uptake from $\mathrm{C}$ grade students is particularly low (2.7\%). However, if gender is taken into account, further differences appear as shown in Table 3.

\begin{tabular}{ccccccc} 
& \multicolumn{5}{c}{ GCSE Mathematics } \\
\multicolumn{2}{c}{ Participation } & A* & A & B & C & Total \\
\hline \multirow{2}{*}{ Female } & No & $466(22.6)$ & $2729(57.5)$ & $7028(88.5)$ & $7401(98.6)$ & $17624(79.2)$ \\
& Yes & $1593(77.4)$ & $2013(42.5)$ & $912(11.5)$ & $108(1.4)$ & $4626(20.8)$ \\
\hline \multirow{2}{*}{ Male } & No & $294(13.5)$ & $1588(35.5)$ & $5125(76.9)$ & $5369(95.7)$ & $12376(65.4)$ \\
& Yes & $1879(86.5)$ & $2888(64.5)$ & $1543(23.1)$ & $240(4.3)$ & $6550(34.6)$ \\
\hline
\end{tabular}

Table 3: Percentage of Advanced level students with each GCSE mathematics grade who completed any AS/2 mathematics, by gender (Dataset B)

A striking element here are the relative proportions which suggest that the higher the GCSE grade the more equal the proportion of male and female students completing some AS/2 mathematics. For example $86.5 \%$ of $A^{*}$ boys complete some Advanced mathematics compared with $77.4 \%$ of $A^{*}$ girls, but for grade B students boys are more than twice as likely to complete some Advanced mathematics $23.1 \%$ and $11.5 \%$ respectively. At grade A the ratio of these percentages (boys:girls) is approximately 3:2, dropping to around 10:9 for A* GCSE students. Analyses of ethnicity and SES measures are complicated by the social and ethnic composition of the sample. Indeed it would be better to try and understand the social patterning of participation by considering this range of social factors together so I will now develop a simple regression model to do this. I also switch to using Dataset $\mathrm{C}$ order to make use of a broader range of social data.

The following model is a single level logistic regression model in which the binary response $(0,1)$ (whether A level students completed any mathematics between 2005-7) for the $i$ th student with prior attainment $x_{i}$ is $y_{i}$. Denoting as $\pi_{i}$ the probability that $y_{i}=1$ gives the general model:

$$
f\left(\pi_{i}\right)=\beta_{0}+\beta_{1} x_{i}+e_{i} \quad \text { (Equation 1) }
$$

There are a number of possible link functions $f\left(\pi_{i}\right)$ which can be used in such logistic regression models but here I adopt the logit link function (Rasbash, Steele, Browne, \& Prosser, 2005) where $f\left(\pi_{i}\right)=\log \left(\pi_{i} /\left(1-\pi_{i}\right)\right)$. Initially this model is run with only the GCSE grade as explanatory variable (see Table 4).

Constant

GCSE mathematics grade (reference category grade C)

Grade B

Grade A
$-5.764(0.155)$

$1.755(0.067)$

3.432 (0.074) 
Table 4: Coefficients from logistic regression model of AS/2 completion by GCSE mathematics grade (standard errors in parentheses)

Substituting the coefficients from Table 4 into Equation 1 gives estimates of the probability of completion which for grades $\mathrm{A}^{*}-\mathrm{C}$ are $0.84,0.56,0.18$ and 0.03 respectively. These probability estimates reflect those in Table 2. This logistic regression model can then be improved by including other explanatory variables. For the purposes of the discussion here first I include gender (Table 5) and then ethnicity (Table 6). I note that I am not concerned here with interaction between these two background variables.

\begin{tabular}{|c|c|c|c|}
\hline & Coefficients & & \\
\hline Constant & $-3.162(0.056)$ & \multirow{2}{*}{\multicolumn{2}{|c|}{ Probability estimates }} \\
\hline Female & $-0.909(0.031)$ & & \\
\hline $\begin{array}{l}\text { GCSE mathematics grade } \\
\text { (reference category grade C) }\end{array}$ & & Male & Female \\
\hline $\mathrm{C}$ & 0 & .041 & .017 \\
\hline $\mathrm{B}$ & $2.047(0.060)$ & .247 & .117 \\
\hline A & $3.871(0.060)$ & .670 & .450 \\
\hline$A^{*}$ & $5.359(0.075)$ & .900 & .784 \\
\hline
\end{tabular}

Table 5: Coefficients for regression model of AS/2 completion by GCSE mathematics grade including gender (left) and resulting probability estimates (right)

The probability estimates on the right hand side of Table 5 highlight the difference between boys and girls but, again, as noted above, the ratio of these probabilities gets closer to 1 the higher up the GCSE grade range. Percentage ratios (boys:girls), which are not an ideal comparative measure but are used for illustrative purposes here, are approximately 8:7 at $\mathrm{A}^{*}$ but drop to 19:9 at grade B. This table highlights gender differences but this is only based upon prior attainment in GCSE mathematics and although girls do better than boys at GCSE generally, their attainment in mathematics is similar (Noyes, 2007). In other words, we might expect students' mathematics grades to be lower than their mean GCSE grade in more cases for girls than for boys. This is important since the literature highlights that subject choices are related to learner self-concept (Ma, 1997; Marsh, 1986) and relative success in different subjects. So differential participation at Advanced level might reflect individual's relative attainment in mathematics more than their absolute attainment relative to their peers. Statistical analyses do not often take this into account.

If the Table 5 probability estimates are recalculated so that the relative attainment in mathematics compared to other GCSEs is taken into account (i.e. the student's mathematics grade is equal to their average GCSE grade) there is a subtle change in these results. For example, probability estimates for students averaging grade A with an A grade in GCSE mathematics are 0.40 (female) and 0.59 (male), lower than in Table 5. This indicates how, across the grade range, relative success has an impact on later completion of AS/2 mathematics, which is to be expected. For all A grade GCSE mathematics students their mathematics score was, on average, half of a grade higher than their average GCSE score. This explains why, when estimating probabilities for students with grade A and averaging grade $\mathrm{A}$, the estimates decrease. Although this analysis is only exploratory, it is clear that relative performance in mathematics compared to overall GCSE performance is associated with likely completion of Advanced level mathematics. So it might be expected that in a school with a high attaining mathematics department (in relation to the whole school attainment at GCSE) a greater proportion of students complete AS/A2. 
Another way in which this data might be examined is by ethnic group and the coefficients of the logistic regression model including ethnicity are shown in Table 6 . Note that only those categories that are statistically significant (at the $5 \%$ level) are included in the table.

\begin{tabular}{ll}
\hline Constant & $-3.351(0.058)$ \\
Female & $-0.928(0.031)$ \\
\hline GCSE mathematics grade (reference category grade C) & \\
Grade B & $2.080(0.060)$ \\
Grade A & $3.936(0.061)$ \\
Grade A* & $5.445(0.076)$ \\
\hline Ethnicity (reference category, White British) & \\
Indian & $1.152(0.059)$ \\
Pakistani & $0.973(0.094)$ \\
Bangladeshi & $0.895(0.194)$ \\
Chinese & $1.455(0.179)$ \\
Any Other Asian Background & $1.103(0.175)$ \\
African & $1.353(0.211)$ \\
\hline
\end{tabular}

Table 6: Regression coefficients of AS/2 mathematics completion including ethnic group, gender and GCSE attainment. (N.B. only ethnicity categories with statistical significance at the $5 \%$ level are included here)

The large coefficients show that some of these ethnic categories are significantly different from the 'White British' base category. The difference in the 'effect' of being White British (0) and Chinese (1.455) on a student's likelihood of completing some Advanced level mathematics is very similar to the differential effect of having attained a GCSE grade A* rather than A (i.e. 5.4 - $3.9=1.5$ ) for any one ethnic group. I use these coefficients to calculate probability estimates of Advanced level completion for grade A students from various ethnic groups as listed in table 7.

GCSE grade A

$\begin{array}{cc}\text { White British } & 0.415 \\ \text { Bangladeshi } & 0.635 \\ \text { Pakistani } & 0.652 \\ \text { Indian } & 0.692 \\ \text { African } & 0.733 \\ \text { Chinese } & 0.753\end{array}$

Table 7: Probability estimated for AS/2 mathematics completion for A grade girls

The differences in these probability estimates (e.g. 0.4 for White British girls compared to 0.7 for Indian girls) are striking but the proportions of some of these ethnic groups out of the whole population is relatively small so the overall effect size (Schagen \& Elliot, 2004) across this cohort and the whole population is relatively much smaller than the gender effect. Nonetheless, this result raises interesting questions about the trajectories of various ethnic groups. Of course what has not been done here is to include SES measures and doing so would no doubt have an effect on some of these coefficients. Data presented below (Table 8) shows that SES has a major impact on GCSE mathematics attainment so this has been embedded in the model to a degree through the prior GCSE attainment variable. The PLASC dataset includes various proxies for SES but here I use the IDACI 
quintiles discussed earlier. . For the level of analysis here I have grouped them into quintiles, based upon national figures for the distribution of IDACI scores.

GCSE

IDACI quintile

\begin{tabular}{cccccc} 
Mathematics & 1 & 2 & 3 & 4 & 5 \\
\hline A* & 5.7 & 3.8 & 2.8 & 1.7 & 0.8 \\
A & 18.9 & 14.1 & 10.5 & 6.6 & 3.8 \\
B & 42.5 & 34.3 & 27.7 & 19.7 & 13.2 \\
\hline C & 68.6 & 60.3 & 52.2 & 41.6 & 31.8 \\
\hline D & 83.5 & 77.1 & 69.9 & 59.1 & 48.6 \\
E & 92.9 & 89.5 & 84.9 & 76.7 & 67.9 \\
F & 97.3 & 95.6 & 93.6 & 89.1 & 83.3 \\
G & 98.4 & 97.7 & 96.8 & 94.7 & 91.9 \\
- & 100.0 & 100.0 & 100.0 & 100.0 & 100.0 \\
\hline
\end{tabular}

Table 8: Cumulative percentages of students in each IDACI quintile attaining various grades (dataset D)

These IDACI scores show, unsurprisingly, that the impact of SES has already had a dramatic effect before any possible transition to A level where there is only a small amount of variation in participation (see Table 9). I have highlighted the $\mathrm{C}$ grade cut off for entry to many post-16 education and employment opportunities and the typical threshold for most students hoping to study Advanced level mathematics (i.e. grade B). There are four times as many students from the first IDACI quintile reaching this grade B entry level than do from the fifth quintile. The question remains as to whether there is further SES attrition from mathematics in the transition to A level. In Table 10 are the proportions of A level students from each quintile who complete some mathematics (Dataset C) and although the differences are not huge there are some small differences.

A level students completing AS/2

Mathematics

\begin{tabular}{ccc} 
& No & Yes \\
\hline IDACI 1 & 72.1 & 27.9 \\
IDACI 2 & 73.6 & 26.4 \\
IDACI 3 & 74.2 & 25.8 \\
IDACI 4 & 75.3 & 24.7 \\
IDACI 5 & 75.4 & 24.6 \\
\hline
\end{tabular}

Table 9: proportions of Advanced level students from each IDACI quintile completing some AS/2 mathematics (dataset B)

However, perhaps it is the case that this difference is merely the effect of lower GCSE attainment from these higher IDACI quintiles. Consider, for example, that in the fifth quintile $4 \%$ get A or above compared to $32 \%$ getting $\mathrm{C}$ or above. For the first quintile group the same percentages are $19 \%$ and $69 \%$. In other words, a much higher proportion of the $\mathrm{C}$ and above group achieves $\mathrm{A}$ or above in the first quintile than in the fifth and I have shown the effect of the prior attainment is very strong. In order to explore this further I compare all students with grade A who proceeded to AS/2 mathematics (Dataset C).

GCSE Grade A students completing 


\begin{tabular}{ccc} 
& \multicolumn{2}{c}{ AS/2 Mathematics } \\
& No & Yes \\
\hline IDACI 1 & 46.2 & 53.8 \\
IDACI 2 & 45.3 & 54.7 \\
IDACI 3 & 43.5 & 56.5 \\
IDACI 4 & 42.0 & 58.0 \\
IDACI 5 & 37.6 & 62.4 \\
\hline
\end{tabular}

Table 10: The percentage of GCSE grade A students who completed AS/2 mathematics at each IDACI quintile

Surprisingly, when the data is not dampened by the large cohort of $\mathrm{C}$ grade mathematicians the differences are reversed and appear even larger. So, $62 \%$ of A grade students from the fifth quintile completed some A level mathematics compared to only $54 \%$ from the first quintile. Understanding this is not straightforward without combining the effect of gender, SES, ethnicity and so on. For example, for these A grade GCSE students in the fifth IDACI quintile, 73\% of male, as compared with $52 \%$ of female students completed some Advanced level mathematics. Further work needs to be undertaken to explore this in greater depth.

Having explored the binary of completing any Advanced mathematics course or not I now look briefly at the level of participation (see description of P0-P4 earlier). It is not simply enough that students are completing an AS in mathematics as one of the express aims of increasing A level participation is to supply STEM courses and businesses with sufficiently well-qualified A level mathematics and further mathematics students. As above, I exemplify this through considering some results with regard to gender (Table 11).

\begin{tabular}{cc|ccccc} 
& & \multicolumn{5}{c}{ Achievement level } \\
& & P0 & P1 & P2 & P3 & P4 \\
\hline \multirow{4}{*}{ Female } & A* & $466(22.6)$ & $168(9.0)$ & $1010(49.1)$ & $181(8.8)$ & $216(10.5)$ \\
& A & $2729(57.5)$ & $655(13.8)$ & $1273(26.8)$ & $53(1.1)$ & $32(0.7)$ \\
& B & $7082(88.5)$ & $472(5.9)$ & $427(5.4)$ & $11(0.1)$ & $2(0.0)$ \\
& C & $7401(98.6)$ & $83(1.1)$ & $25(0.3)$ & & \\
\hline \multirow{4}{*}{ Male } & A* & $294(13.5)$ & $121(5.6)$ & $1043(48.0)$ & $242(11.1)$ & $473(21.8)$ \\
& A & $1588(35.5)$ & $674(15.1)$ & $1942(43.4)$ & $144(3.2)$ & $128(2.9)$ \\
& B & $5125(76.9)$ & $762(11.4)$ & $748(11.2)$ & $25(0.4)$ & $8(0.1)$ \\
& C & $5369(95.7)$ & $163(2.9)$ & $77(1.4)$ & & \\
\hline
\end{tabular}

Table 11: Numbers (and percentages) of students with each GCSE grade completing AS/2 mathematics at various levels, by gender

In addition to gender differences in completion of some Advanced level mathematics here we see that there are also clear differences in the levels of participation by male and female students at each GCSE grade level. Further Mathematics (P3/4), which is the preferred level of qualification for many mathematically demanding higher education courses, is completed by nearly one third of the male $A^{*}$ students compared with one fifth of female students. Secondly, the difference in completion of Advanced level mathematics (P2) from GCSE grade A students is notable: $27 \%$ of females compared with $43 \%$ of males. Thirdly completion of Advanced or Advanced supplementary mathematics (P1/2) by B-grade GCSE students is about twice as much for males as females. Leaving gender aside, these data show that participation in Further Mathematics is heavily skewed, drawing largely from A* GCSE students. It might be expected that these patterns would vary by ethnic group and SES. 
In the above my aim has been to outline one method for analysing the massive and complex data of the NPD and to exemplify this analysis with regard to student participation, completion and achievement in A level mathematics.

\section{Discussion}

So what does this exploration of the NPD data tell us? That the social axes of SES, ethnicity and gender work together to shape GCSE mathematics attainment and, partly as a result of this, impact the likelihood and level of participation in university-entrance level mathematics. Socio-economic status has already impacted students' likelihood of completing some Advanced mathematics by the time they reach GCSE level (Year 11). A much smaller proportion of students with high IDACI scores (indicating lower socio-economic status) achieve the grades normally required to be admitted onto Advanced level mathematics courses. Exploring the impact of SES is limited using the data available but my results do indicate that a higher proportion of GCSE A grade students from more disadvantaged backgrounds complete some Advanced mathematics than do their peers from less disadvantaged backgrounds. I would like to stress that, whereas the effect upon GCSE mathematics attainment is quite clear, making a valid assessment of the impact on Advanced level mathematics completion is more problematic. Exploring the impact of social differentiation requires a more nuanced analysis than has been possible here.

The greatest effect upon one's likelihood of participation in A level mathematics, beyond prior attainment at GCSE, is that of being female, although I have made it clear that relative prior attainment in mathematics compared with other GCSE subjects will impact the likelihood of completing some mathematics, and this might be different for girls and boys. Also, looking across the range of prior GCSE attainment shows that this gender difference is not as great at grade $\mathrm{A}^{*}$ as for those students obtaining GCSE grade A or B. Given the overall numbers of students achieving each of these grades, the increasing participation gap as the GCSE grade gets lower is exacerbated by the increased proportion of the cohort at each GCSE grade. For example, if girls achieving A* completed Advanced level mathematics in the same proportion as boys $(86.5 \%)$ this would be an extra 188 students but a similar calculation, matching the girls' rate of completion with that of boys, at grade A would yield 1045 students and at grade B a further 922 . Of course I am not taking account of the relative performance in mathematics compared with other subjects here but this does reinforce the plea by Matthews and Pepper that "in order to properly increase participation recruitment would need to become less exclusive" (Matthews \& Pepper, 2007, 5). It seems reasonable to propose that understanding why this group of GCSE A/B girls do not continue and then acting to address this would be a good way forward. Even if half of the extra girls above (i.e. half of $1045+922$ ) were to have continued this would have increased mathematics participation by nearly $10 \%$ overall. The increasing body of research into girls' attitudes to the study of mathematics (Fennema \& Leder, 1990; Jacobs \& Bleeker, 2004; Mendick, 2005; Solomon, 2007) suggests that the female participation issue emerges at a much younger age and therefore it would need to be tackled well before these students approached the age at which they are expected to decide on advanced studies.

I have shown that the ethnicity of students has a significant impact upon their likelihood of completing some university-entrance level mathematics. My results suggest that some ethnic groups are nearly twice as likely to participate as their White British peers. Having said that, the size of each of these ethnic groups is typically smaller than $1 \%$ of the whole cohort so the effect size is not as great as that for girls, which applies to half of the population. This variation across ethnic groups suggests a variation of cultural perspectives on the value of learning Advanced level mathematics. Such perspectives are being discussed in (e.g. Archer, 2002; Ball, Reay, \& David, 2002) - but an even subtler focus on issues of subject choice at the GCSE/A level interface is necessary. 
In summarizing these findings I need to reiterate that the interaction of these effects has not been thoroughly explored here and there is no doubt considerable intertwining of the axes of SES, gender and ethnicity. Connolly (2006) argues that social class and ethnicity (in that order) have greater impact upon GCSE attainment than does gender. This might well be the case here although it has not been the express aim of this paper to quantify the relative impact of these factors. I have made it clear that we need to not only look at the differences between various groups but need to also consider the effect size (Schagen \& Elliot, 2004) which is a reflection of how large a proportion of the cohort is affected by any one category; gender has, in that sense, a bigger effect than, say, being Chinese.

Many of these findings reflect what is already known although the data reported here help to quantify these differences. Disrupting the choice 'principles' which lead to these patterns of participation/completion, in order to increase participation in Advanced mathematics, is not straightforward as action would require the diverse sections of the mathematics education community to engage with the social/cultural register referred to earlier. School and classroom (mathematics) cultures are not easy to change. Ball et al's 'two registers of meaning and action' are very much overlaid in school mathematics as the cognitive/performative register is heavily imbued with cultural/social meanings. For example, data from the GMAP Project's surveys of Year 11 students include many examples of high attaining GCSE students (predicted A/A*) who don't consider themselves to be successful in mathematics compared to their peers - and so their predisposition towards mathematical study do not match their actual capacity to be successful. The exploratory statistical analysis above has little power to explain why certain groups (grade B students, girls, etc) tend to participate at lower rates. It can, however, be used to spot patterns and suggest where small changes might have a bigger impact on participation.

Finally, these findings are helping to frame the research questions which underpin the design of the case study work which is now being undertaken in a group of secondary schools in the subsequent phases of Project GMAP. Other studies in mathematics education (for example those reported in the Introduction) have made various attempts to explore the fabric of students' everyday mathematics learning experiences and how these impact on attainment, recruitment and attrition. The GMAP Project will add to this work by exploring how communities, schools, families and peer groups contribute to the development of dispositions which impact on students' decision to continue or cease their mathematical studies, thus generating the socially differentiated patterns of participation explored above.

\section{Acknowledgements}

I am grateful to the Economic and Social Research Council for funding the GMAP Project (RES061-25-0035), the project advisory group for their thoughtful, probing questioning of my work and the reviewers who provided detailed, critical yet encouraging responses to my earlier draft.

\footnotetext{
${ }^{1}$ ACORN (http://www.caci.co.uk/ACORN/acornmap.asp) is a system assigning individual address postcodes to 56 social categories. The top level, which is the only level available in the NPD, has five categories: wealthy achievers, urban prosperity, comfortably off, moderate means and hardpressed.

${ }^{2}$ The Income Deprivation Affecting Children Index (IDACI) gives a score from 0 (low deprivation) to 1 (high deprivation) for each small cluster of postal addresses across England. The IDACI measure is an aggregated score for a few students who might have quite different social backgrounds.

${ }^{3}$ Free Standing Mathematics Qualifications (FSMQs) are not tied to any particular Advanced level qualification but are worth the same credit as one third of an Advanced Supplementary qualification.
} 
Students who need to complement their chosen course of study with a particular aspect of mathematics (e.g. statistics) might study a FSMQs.

\section{References}

Archer, L. 2002. Change, culture and tradition: British Muslim pupils talk about Muslim girls' post16 choices. Race Ethnicity and Education 5, no 4: 359-376.

Ball, S., Bowe, R., \& Gewirtz, S. 1996. School choice, social class and distinction: the realization of social advantage in education. Journal of Education Policy 11, no 1: 89-112.

Ball, S., Davies, J., David, M., \& Reay, D. 2002. 'Classification' and 'judgement': social class and the 'cognitive structures' of Higher Education. British Journal of Sociology of Education 23, no 1: $51-72$.

Ball, S., Maguire, M., \& Macrea, S. 2000. Choice, pathways and transitions post-16: New youth, new economics in the global city. London: RoutlegeFalmer.

Ball, S., Reay, D., \& David, M. 2002. 'Ethnic choosing': minority ethnic students, social class and higher education choice. Race Ethnicity and Education 5, no 4: 333-357.

Bourdieu, P., \& Wacquant, L. 1989. Toward a reflexive sociology: a workshop with Pierre Bourdieu. Sociological Theory 7, no 1: 26-63.

Brown, M., Brown, P., \& Bibby, T. 2008. "I would rather die": reasons given by 16-year-olds for not continuing their study of mathematics. Research in Mathematics Education 10, no 1: 3-18.

Connolly, P. 2006. The effects of social class and ethnicity on gender differences in GCSE attainment: A secondary analysis of the youth cohort study of England and Wales 1997-2001. British Educational Research Journal 32, no 1: 3-21.

Emery, J. 2007. Uptake of GCE A-level subjects in England 2006. Cambridge: Cambridge Assessment.

Fennema, E., \& Leder, G. 1990. Mathematics and gender: influences on teachers and students. New York: Teachers College Press.

Gago, J. M. 2004. Increasing human resources for science and technology in Europe. Brussels: European Commission.

Gorard, S. 2008. Who is missing from higher education? Cambridge Journal of Education 38, no 3: 421-437.

Hernandez-Martinez, P., Black, L., Williams, J., Davis, P., Pampaka, M., \& Wake, G. 2008. Mathematics students' aspirations for higher education: class, ethnicity, gender and interpretive repertoire styles. Research Papers in Education 23, no 2: 153-165.

Jacobs, J., \& Bleeker, M. 2004. Girls' and boys' developing interests in math and science: do parents matter? New Directions for Child and Adolescent Development 106: 5-21.

Leckie, G., \& Goldstein, H. 2009. The limitations of using school league tables to inform school choice. Journal of the Royal Statistical Society: Series A.

Ma, X. 1997. Reciprocal relationships between attitude towards mathematics and achievement in mathematics. The Journal of Educational Research 90, no 4: 221-229. 
Marsh, H. 1986. Verbal and math self-concepts: An internal/external frame of reference model. American Educational Research Journal 23, no 1: 129-149.

Matthews, A., \& Pepper, D. 2007. Evaluation of participation in A level mathematics: final report. London: Qualifications and Curriculum Authority.

MEI. 2008. MEI investigation into the increase in C1 candidates in January 2008. London: Mathematics in Education and Industry Group.

Mendick, H. 2005. Mathematical stories: why do more boys than girls choose to study mathematics at AS-level in England? British Journal of Sociology of Education 26, no 2: 235-251.

Noyes, A. 2007. Rethinking School Mathematics. London: Paul Chapman Publishing.

QCA. 2008. Mathematics Pathways. Retrieved 9th March, 2009, from www.qca.org.uk/qca_14400.aspx

Rasbash, J., Steele, F., Browne, W., \& Prosser, B. 2005. A user's guide to MLWin (version 2.0): Centre for Multilevel Modelling, University of Bristol.

Reay, D., Davies, J., David, M., \& Ball, S. 2001. Choices of degree or degrees of choice? Class, 'race' and the higher education choice process. Sociology 35, no 4: 855-874.

Roberts, G. 2002. SET for success: The supply of people with science, technology, engineering and mathematics skills. London: Department for Education and Science.

Schagen, I., \& Elliot, K. (Eds.). 2004. But what does it mean? The use of effect sizes in educational research. Slough NFER.

Smith, A. 2004. Making Mathematics Count. London: The Stationery Office.

Solomon, Y. 2007. Experiencing mathematics classes: ability grouping, gender and the selective development of participative identities. International Journal of Educational Research 46: 819.

Wiliam, D., Brown, M., Kerslake, D., Martin, S., \& Neill, H. 1999. The transition from GCSE to Alevel in mathematics: a preliminary study. Research in Mathematics Education 1: 41-56.

Wolf, A. 2002. Does Education Matter? Myths about education and economic growth. London: Penguin. 